\title{
Study of the Potential of a Local Geoid Model for Extracting the Orthometric Heights from GPS Measurements in Topographic Works
}

\author{
Yehia H. Miky ${ }^{1,2}$ Reda Yaagoubi ${ }^{3} \quad$ Ahmed El Shouny*1,4 \\ 1. King AbdulAziz University, Department of Geomatics, Faculty of Environment Design, Jeddah, Saudi Arabia \\ 2.Faculty of Engineering, Aswan University, Aswan, Egypt \\ 3. College of Geomatics and Surveying Engineering, IAV Hassan II, Rabat Morocco. \\ 4.Survey Research Institute, National Water Research Center, Giza, Egypt
}

\begin{abstract}
Due to the rapid development and expansion of geodetic applications, the determination of orthometric heights in an accurate manner is considered as one of the most required conditions to carry out such projects. Obtaining orthometric heights using traditional methods of levelling is time and cost consuming. Hence, investigating other techniques that provide the same accuracy, as leveling methods, but requiring less time and cost is very gainful. Recently, satellite positioning techniques and their applications are being used increasingly in geodetic projects. So, it is interesting to study the efficiency of such techniques for obtaining orthometric heights. GPS methods provide highly accurate measurement of ellipsoidal heights. However, the conversion of ellipsoid heights to orthometric heights may be achieved using geoid models. The objective of this research is to study the efficiency of using a local geoid model as an alternative method to obtain orthometric heights from GPS measurements. This paper proposes a methodology to generate such local geoid models. Then, the results of using the generated local geoid model for Jeddah city in Saudi Arabia are presented. These results indicate that the difference among estimated undulations values from the local geoid model and undulations values calculated from leveling techniques ranges from $1.8 \mathrm{~cm}$ to $-1.1 \mathrm{~cm}$. with a maximum standard deviation of $56 \mathrm{~mm}$. These results confirm that the creation of a local geoid model is an effective method that gives the required accuracy for topographic works.
\end{abstract}

Keywords: GPS/Levelling method, Local geoid model, Krigging method.

\section{Introduction}

With the advent of satellite-based technology, especially Global Positioning System (GPS), and it's wide usage on different fields of surveying and geomatics, it becomes too easy to obtain three dimensional coordinates latitude, longitude, and ellipsoid height (h), relative to ellipsoid surface, with high accuracy. However, many of engineering projects depend upon the so-called orthometric height $(\mathrm{H})$, relative to geoid surface represented by Mean Sea Level (M.S.L.). In order to transform ellipsoid heights into orthometric heights, we should accurately know the difference between both of these heig=hts, which is called geoid undulation $(\mathrm{N})$. Determination of the geoid undulation value isn't an easy task especially with insufficient available data along the study area. The commonly used procedures that can provide this geoid heights are categorized into three groups: Geometric, gravimetric geoid models, and Earth geopotential models (EGMs). On one hand, EGMs provide global geoid models of the Earth's gravity field based on satellite gravity mission [Förste et al., 2006]. On the other hand, geometric and gravimetric models can be developed for various areas, either locally or regionally. [Chen and Yang, 2001 - Seyed M. K. et al., 2016 - El Shoney et al., 2017].

The geometric method uses GPS/Levelling data without the need of gravity measurements in geoid determination. This method is suitable especially for relatively small areas with less variation in the mass density and distribution on the region of interest. While the gravimetric method is widely used throughout the world for the geoid determination because it is the most precise method. It consists of determining a geoid using gravity measurements. These two methods may be combined together to calculate this geoidal undulation and deflection by using available data obtained from both gravimetric and geometric approaches [Featherstone, 1998 - Erol and Celic, 2004 - Tripathi R.K. and Tripathi M., 2015 - El Shoney et al., 2017].

In this study, the geometric method is used for creating a local geoid model for the study area using GPS/leveling observations to decide to what extent we can replace levelling works with GPS observations to determine orthometric heights. To achieve this goal, a kriging interpolation method is used to generate geoid undulation for the region of interest. In addition, this interpolation method allows assessing the precision of such a geoid undulation model.

\section{Local Geoid Model}

Geoid models may be classified according to area they covered into global and local geoid models. Investigation of high accurate determination of these geoid models takes an important place in the recent studies of geodesy. A 
large number of Global Geopotential Models (GGMs) have been released and developed in the last few years such as the Ohio State University (OSU-91A), The Earth Geopotential Models (EGM1996), and (EGM2008) which considered the most popular used one. Several studies have been performed to evaluate the precision of these geoid models in obtaining orthometric heights from ellipsoid heights. [Dawod et al., 2010 - Al-Krargy et al., 2014].

In relatively small areas, local geoid model may be used in place of GGMs. These local geoid models may be created using geometric or gravimetric approaches. The geometric approach is widely used due to the extensive use of GPS and leveling techniques. Many previous studies were interested in investigating these GPS/leveling methods for the creation of local geoid models as [Zhong, 1997 - Featherstone et al. 1998 - Erol and Celic, 2004 - Erol and Erol, 2013 - Seyed M. K. et al., 2016]. Also, the optimal combination of GPS and leveling observations along with the available geoid models were investigated by [Featherstone, 2000 Soltanpour et al., 2006 - You, 2006].

The ellipsoid height $(\mathrm{h})$ is accurately obtained from GPS measurements. The orthometric height $(\mathrm{H})$ that is calculated according to the geoid is determined by geometric leveling. The undulation of geoid is defined as the distance between a point on the surface of the geoid and its projection on surface of the ellipsoid of reference according to the normal of the ellipsoid (n'). the deflection is defined as the angle between the normal to the ellipsoid (n') and the vertical to the geoid (n) as shown in figure (1). The relation among the ellipsoid height (h), the orthometric height $(\mathrm{H})$ and the undulation $(\mathrm{N})$ can be calculated using equation no. (1).

$$
\begin{aligned}
& \underset{\text { Where, }}{N}=h-H \\
& \mathrm{~h}: \text { ellipsoidal height, } \\
& \mathrm{H}: \text { orthometric height, and } \\
& \mathrm{N} \text { : geoid undulation. }
\end{aligned}
$$

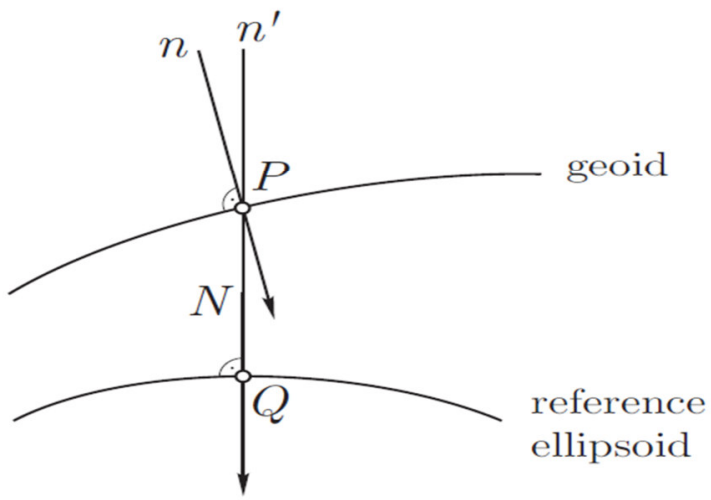

Figure 1. Relation between ellipsoidal height, orthometric height and geoid undulation (geoid height)

[Hofmann-Wellenhof and Moritz, 2006]

The geoid heights at any other GPS measurement points can be calculated using analytical or graphical interpolation methods depending on the known geoid heights of some surrounding reference points. These interpolation surface modeling methods refers to as the process of generating a surface through the study area with available data set and it is aimed at formulating an object in a grid system, in which each grid cell contains an estimate of the object that is representative for that particular location. [ Elshouny and Yakoub, 2015].

There are several important factors that affect the accuracy of GPS/ Leveling method for creation local geoid model. These factors are; [Erol and Çelik, 2004]

1. The distribution and the number of GPS/ Leveling reference points. These points must be distributed homogeneously into the coverage area of the model. Also, they have to be chosen according to the expected changes of the interpolated geoid surface.

2. The accuracy of the ellipsoidal heights (h) (derived from GPS measurements) and the orthometric heights $(\mathrm{H})$ (derived from levelling measurements).

3. Characteristic of the mass distribution in the area of interest.

4. Used the appropriate interpolation method while modelling the geoid.

Regarding this last point, there are different interpolation algorithms where each of them may provide different results when interpreting data. Some of the interpolation algorithms that may be used for generating local geoid models are: Polynomial Regression, Inverse Distance Weighting to Power (IDW), Natural Neighbor, Triangulation linear interpolation, and Kriging [El- Hallaq, 2012 - Elshouny and Yakoub, 2015].

The Kriging method, compared to other interpolation techniques, provide an estimation of the error during the interpolation process because it has the advantage of integrating geo-statistical constraints in the process of 
interpolation based upon spatial variance. Kriging interpolation methods have proven to be useful and popular in many fields as well as geodesy. The kriging interpolation weights the surrounding measured values to derive a prediction for unmeasured locations [Oliver and Webster, 1990]. However, in kriging, the weights are based not only on the distance between the measured points and the prediction location but also on the overall spatial arrangement of the measured points. Kriging assumes that the distance or direction between sample points reflects a spatial correlation that can be used to explain the variation in the surface [Longley et.al, 2010]. To use the spatial arrangement in weights assignment, the spatial autocorrelation must be quantified through empirical semi-variograms.

The constructed semi-variogram of the data is used to weight nearby sample points when interpolating, also it provides a means for users to understand and model the directions (e.g., north-south, east-west) trends of their data. The semi-variogram can have one of the following models: circular, spherical, exponential, Gaussian, and linear. There are two kriging methods: ordinary and universal. The ordinary kriging, the most common method, assumes that the constant mean is unknown, while the universal kriging assumes that there is an overriding trend in the data and this trend is modeled by a polynomial. Kriging is multi-steps process including: exploratory statistical analysis of the data, variogram modeling, creating the surface, and (optionally) exploring a variance surface. Kriging uses the following equation no. (2) [Qulin Tan and Xiao Xu, 2014]:

$$
\text { Where, } \quad Z\left(s_{0}\right)=\sum_{i=1}^{N} \lambda_{i} Z\left(s_{i}\right)
$$

$\mathrm{Z}\left(\mathrm{S}_{\mathrm{i}}\right)=$ the $\mathrm{i}$-th position of the measured value,

$\lambda_{i}=$ the $\mathrm{i}$-th position measurement values of the unknown weight,

$\mathrm{S}_{0}=$ the predicated position, and

$\mathrm{N}=$ the number of measurements.

Kriging is a very flexible gridding method where by the default parameters may be accepted to produce an accurate of the source data; alternatively, Kriging can be custom-fit to a data set by specifying an appropriate variogram model. Kriging can be either an exact or a smoothing interpolator depending on the user specified parameter [Elshouny and Yakoub, 2015].

\section{Numerical Case Study}

An early study for the geoid modeling in the Kingdom of Saudi Arabia (KSA) was conducted by Algarni [1997]. He employed the GPS points and the orthometric heights to derive the geometrical geoid model using a leastsquares fitting model. Currently, there are two existing geometrical geoid models, the first is the KSA geoid model by Ngiboglu [2008], derived from the GPS points co-located with the basic levelling network established by the Arabian-American Oil Company (ARAMCO). The variation in the density of points distribution is noticeable in the western region where the point measurements are rare, compared to the eastern region where there is a highly coverage particularly over the oil field areas. The second geoid model is produced by the Saudi Ministry of Municipality and Rural Affairs (MOMRA) as described by Alrajhi et al. [2009]. The MOMRA model is combined with a first-order levelling network, high precision GPS measurements attached to the International Terrestrial Reference Frame (ITRF2000), and EGM08 [Pavlis et al., 2012]. The least-squares collocation was utilized for fitting the model with the GPS-levelling data and EGM08 in an iterative way [see Alothman et al. 2011, 2012, 2013].

In this paper, the study area of this research is located in the middle part of Jeddah city on the west coast of the Kingdom of Saudi Arabia, in the middle of the eastern shore of the Red sea. The selected study area located in the middle part of Jeddah city and with an approximate total area of (100) kilometers square as represented in figure (2). 


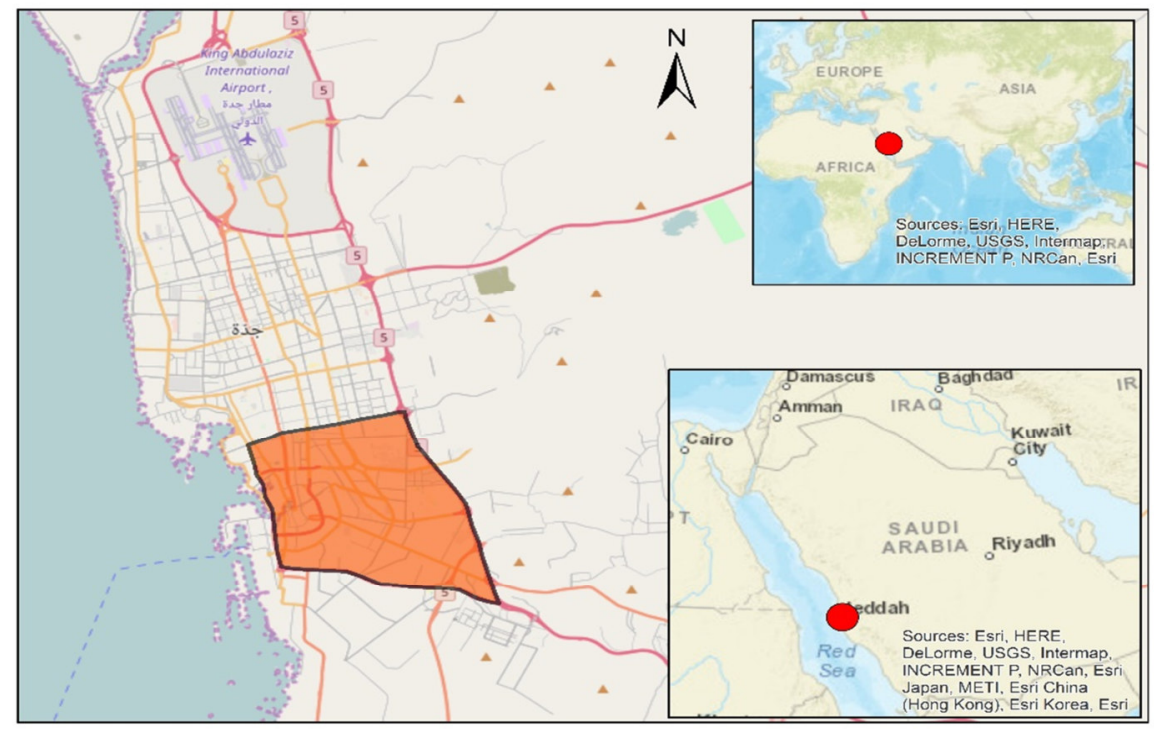

Figure 2. The selected study area

\subsection{Designing the network of reference points}

Available data used in the study consists of (19) reference points of second order class established by Jeddah Municipality. These points have been selected from all available points after exclusion of missing and bad condition points as a result of field reconnaissance stage for all available existing points in the study area. These points are defined by their accurate geographic coordinates latitude $(\Phi)$, longitude $(\lambda)$, in addition to their ellipsoid heights $(\mathrm{h})$. Also, orthometric heights $(\mathrm{H})$ of these available points were determined according to the second order class levelling - standards and specifications. The distribution of these (19) reference points along the study area is represented in figure (3).

Before starting the densification of the existing reference points, it was important to study their distribution to determine locations where densification is required. The newly established reference points aim to improve the geometry of the network that will be used for generating local geoid model of the study area. Three newly reference points were added to the existing (19) reference points as shown in figure (3). These reference points were observed using GPS observations in order to determine their accurate geographic coordinates and ellipsoid heights. Also, as detailed in section 3.2, the new reference points were observed using geometric leveling process to obtain their orthometric height. 


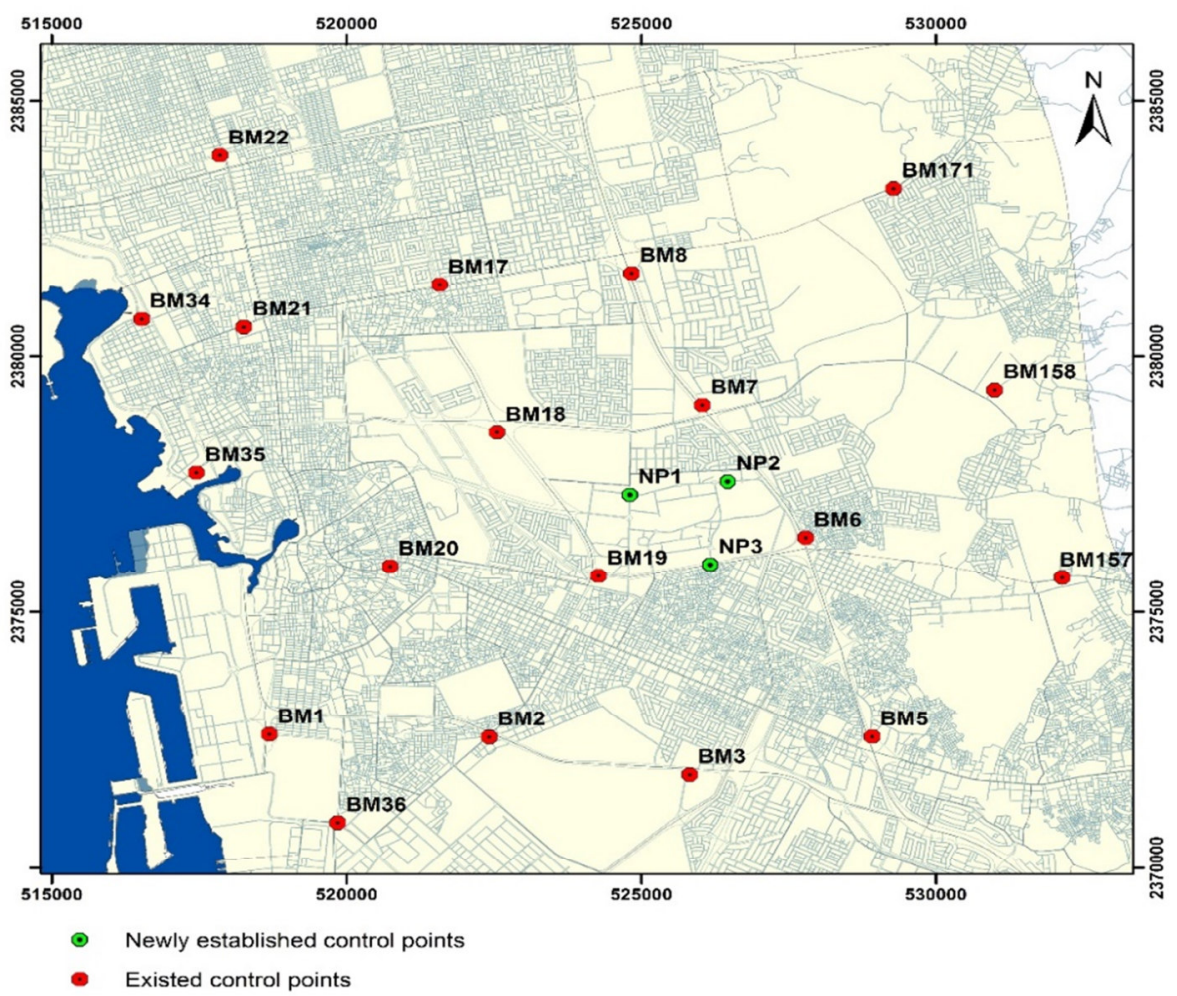

Figure 3. The distribution of existed and newly established reference points along the study area

\subsection{Levelling Observations}

A closed leveling network was performed in order to check the quality of orthometric heights of existing reference points and also to calculate the heights of the newly established reference points. This network is composed by six reference points, three of them were already established with known elevation while the other three points are newly established where the elevations needs to be calculated. This circuit were deigned assuming that only 2 of these 3 known reference points have known elevations in order to check the quality of the existing points used in the leveling network. Two ways leveling (forward and backward) between these points were observed with the reading sequences "backward - forward - forward - backward" and then "forward - backward - backward - forward" to have redundant measurements to eliminate blunder errors and to enable performing least-squares adjustment technique for calculating unknown elevations. The design of this network consists of 18 routes between reference points with about (47) km length, are shown in figure (4).

To achieve standards of second order leveling, a Leica Sprinter $150 \mathrm{M}$ digital level, with $0.6 \mathrm{~mm}$ precision, was used during observations (figure 5a). According to the second order standards the maximum sight distance is 70 meters and the differences between the backward and forward sight distance should never exceed 5 meters per setup to avoid columniation errors. Also, the maximum allowable value of mis-closure between the two leveling ways (backward and forward) is $\pm 8 \sqrt{ } \mathrm{L}$ in $\mathrm{mm}$ where $\mathrm{L}$ is the length of the leveling (only one way) in kilometers [Adm and Bossler, 1984]. After this, the final orthometric height differences of each route was calculated by the mean of the two leveling ways values as shown in table (1).

A Least-squares technique was then performed to obtain the optimal solutions of orthometric heights for the 4 unknown reference points using equation no. (3) (on of them as check point and the three others as new points). The final orthometric heights of all reference points along the study area are included also in table (1).

where:

$$
X=\left|\begin{array}{cc}
b m & 12 \\
b m & 03 \\
b m & 06 \\
f & 174
\end{array}\right|=\left(A^{T} . W . A\right)^{-1} \cdot A^{T} . W . L
$$

$\mathrm{X}$ : is elevation unknown values,

$\mathrm{A}, \mathrm{A}^{\mathrm{T}}$ : is design matrix, and its transpose matrix,

$\mathrm{W}$ : weight matrix, and

L : observations matrix 


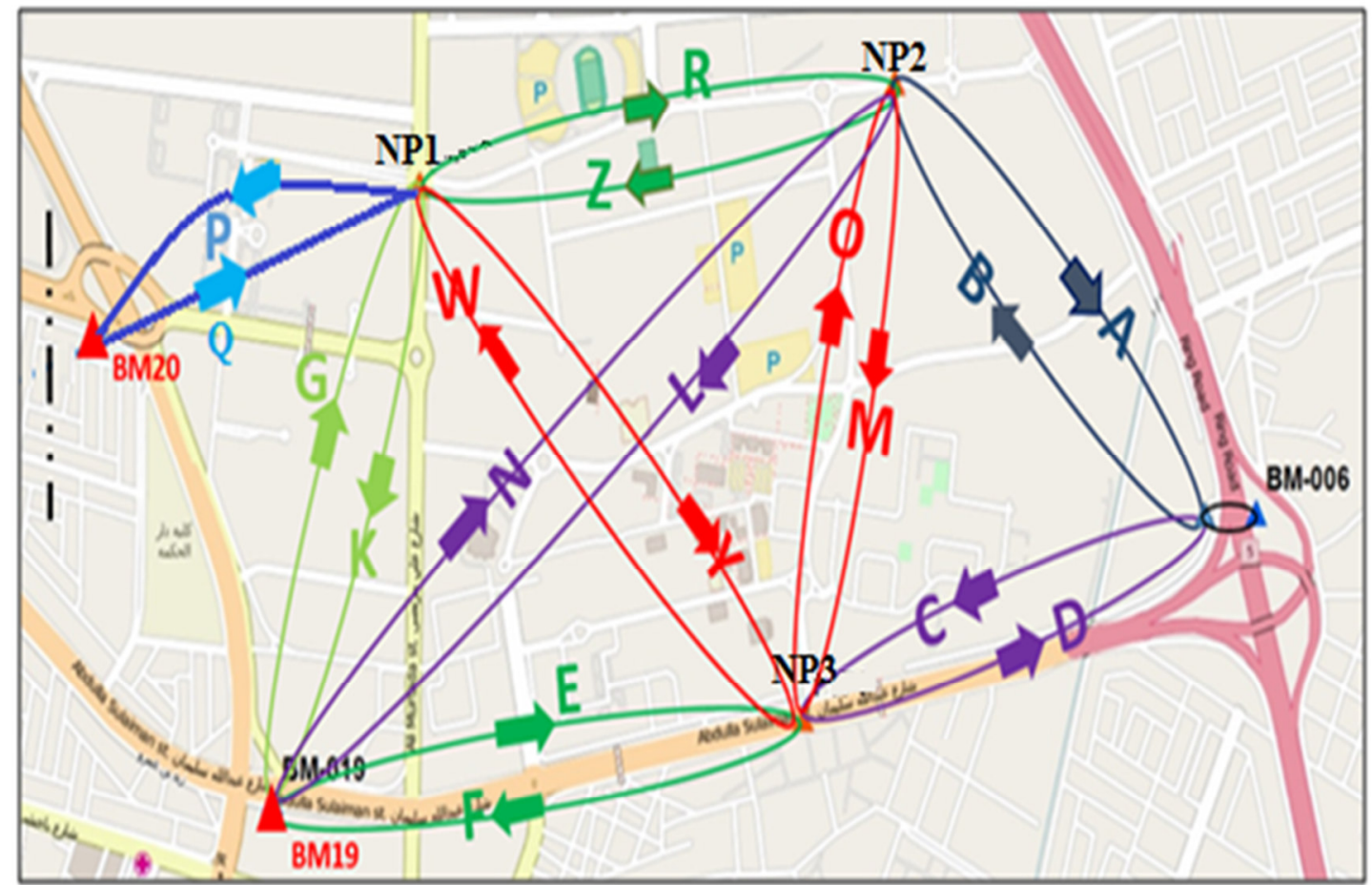

Figure 4. Leveling circuit design and its routes between reference points

\subsection{GPS Observations}

A Differential GPS mission was carried out for all the 22 reference points used along the study area to calculate their precise three dimensional coordinates including latitude, longitude, and ellipsoid heights. The GPS network was designed as an over-constrained network with two fixed points with known coordinates. The observations were performed using (10) successive sessions, as shown in figure (6), with five Leica Viva GNSS instruments (figure 5b). Two instruments were installed as bases and the three other ones as rovers. All GPS observations were in static mode with duration of a about one hour for each session. Dilutions of precision, number of available satellites and best observations period were taken into consideration during observation sessions.

Table (1): All leveling routes data and final obtained orthometric heights.

\begin{tabular}{|c|c|c|c|c|c|c|c|c|c|}
\hline Direction & $\begin{array}{l}\text { Route } \\
\text { ID }\end{array}$ & Route Points & $\begin{array}{l}\text { Each Route } \\
\text { Length (m) }\end{array}$ & $\begin{array}{l}\text { Total Route } \\
\text { Length (m) }\end{array}$ & $\begin{array}{c}\text { Height } \\
\text { Differences (m) }\end{array}$ & $\begin{array}{l}\text { Mis- } \\
\text { closure } \\
(\mathrm{m})\end{array}$ & $\begin{array}{l}\text { Allowable } \\
\text { Mis-closure }\end{array}$ & $\begin{array}{l}\text { Correction } \\
\text { Values }\end{array}$ & $\begin{array}{c}\text { Final } \\
\text { orthometric } \\
\text { heights }\end{array}$ \\
\hline Go & A & NP2-BM6 & 1975.855 & \multirow{2}{*}{3980.55} & 6.6199 & \multirow{2}{*}{0.0029} & \multirow{2}{*}{0.019} & 0.0014 & 6.6185 \\
\hline Return & B & BM6-NP2 & 2004.695 & & -6.6170 & & & 0.0015 & -6.6185 \\
\hline Go & $\mathrm{C}$ & NP3-BM6 & 1895.87 & \multirow{2}{*}{3828.162} & 10.5681 & \multirow{2}{*}{0.0148} & \multirow{2}{*}{0.019} & 0.0075 & 10.5608 \\
\hline Return & D & BM6-NP3 & 1932.292 & & -10.5533 & & & 0.0073 & -10.5608 \\
\hline Go & E & BM19-NP3 & 1957.09 & \multirow{2}{*}{3920.492} & 11.2787 & \multirow{2}{*}{-0.0115} & \multirow{2}{*}{0.019} & 0.0058 & 11.2811 \\
\hline Return & $\mathrm{F}$ & NP3-BM19 & 1963.402 & & -11.2869 & & & 0.0058 & -11.2811 \\
\hline Go & G & BM19-NP1 & 2018.952 & \multirow{2}{*}{4100.372} & 4.7110 & \multirow{2}{*}{0.019} & \multirow{2}{*}{0.020} & 0.0094 & 4.7016 \\
\hline Return & $\mathrm{K}$ & NP1-BM19 & 2081.42 & & -4.692 & & & 0.0096 & -4.7016 \\
\hline Go & W & NP3- NP1 & 2392.95 & \multirow{2}{*}{4764.84} & -6.609 & \multirow{2}{*}{0.0099} & \multirow{2}{*}{0.021} & 0.005 & -6.6049 \\
\hline Return & $\mathrm{Y}$ & NP1- NP3 & 2371.89 & & 6.600 & & & 0.0049 & 6.6049 \\
\hline Go & M & NP2- NP3 & 1836.61 & \multirow{2}{*}{3700.32} & -3.9359 & \multirow{2}{*}{0.0142} & \multirow{2}{*}{0.019} & 0.0071 & $0-3.943$ \\
\hline Return & $\mathrm{O}$ & NP3- NP2 & 1863.71 & & 3.9501 & & & 0.0071 & 3.9430 \\
\hline Go & $\mathrm{R}$ & NP1- NP2 & 1716.397 & \multirow{2}{*}{3417.787} & 10.5393 & \multirow{2}{*}{0.0005} & \multirow{2}{*}{0.018} & 0.0025 & 10.53905 \\
\hline Return & $\mathrm{Z}$ & NP2- NP1 & 1701.390 & & -10.5388 & & & 0.0025 & -10.53905 \\
\hline Go & $\mathrm{N}$ & BM19-NP2 & 3811.450 & \multirow{2}{*}{7327.53} & 15.2274 & \multirow{2}{*}{-0.0126} & \multirow{2}{*}{0.027} & 0.0066 & 15.2340 \\
\hline Return & $\mathrm{L}$ & NP2-BM19 & 3516.08 & & -15.240 & & & .00600 & $0-15.234$ \\
\hline Go & $P$ & NP1-BM20 & 5920.06 & \multirow{2}{*}{11865.76} & -21.135 & \multirow{2}{*}{-0.016} & \multirow{2}{*}{0.027} & 0.0079 & -21.127 \\
\hline Return & Q & BM20- NP1 & 5945.70 & & 21.119 & & & 0.0081 & 21.127 \\
\hline
\end{tabular}


Leica Geo-Office software (LGO) was used to process the collected GPS data with a 95\% confidence level. During the processing, the ambiguity was first solved. Also, errors such as antenna phase center and ionospheric and tropospheric delays were corrected. Precise ephemeris was used instead of the Broadcasted one to increase the accuracy of the adjusted coordinates of reference points. After LGO processing and adjustment processes, the final coordinates of all points with their horizontal precision are calculated. Table 2 contains the calculated coordinates and ellipsoid heights obtained from GPS measurements with their corresponding horizontal and vertical precision, the orthometric height obtained from levelling process, and also the undulation value of each reference point.

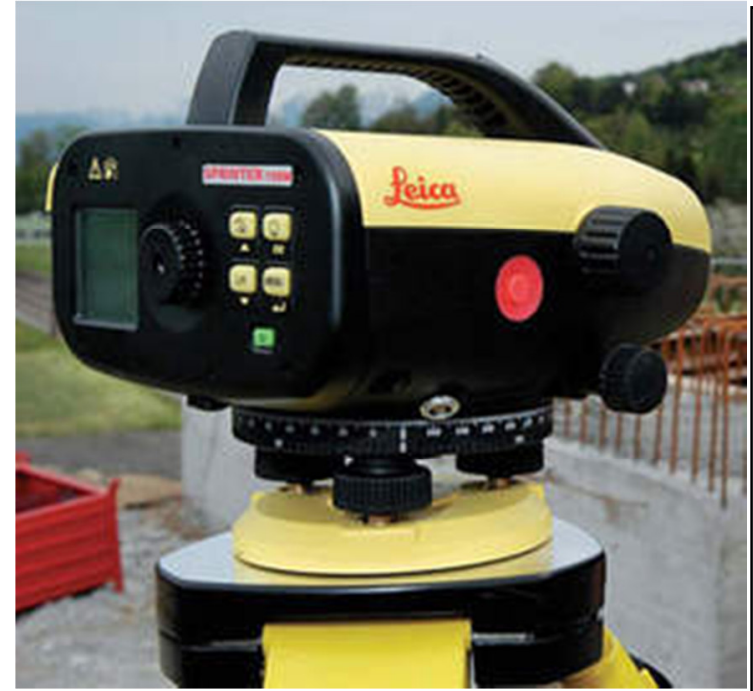

(a) Leica sprinter $150 \mathrm{~m}$

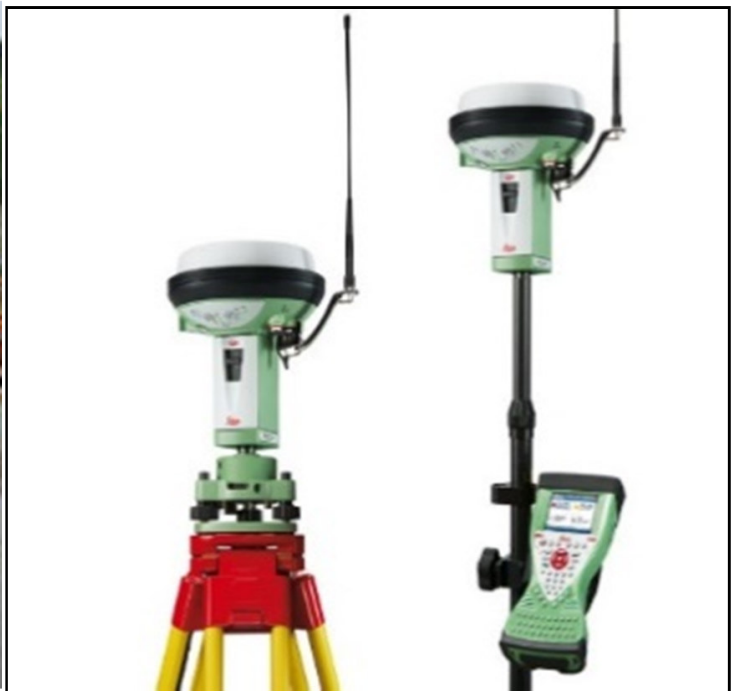

(b) Leica viva GS 15

Figure 5. Level and GPS instruments used in the observation processes

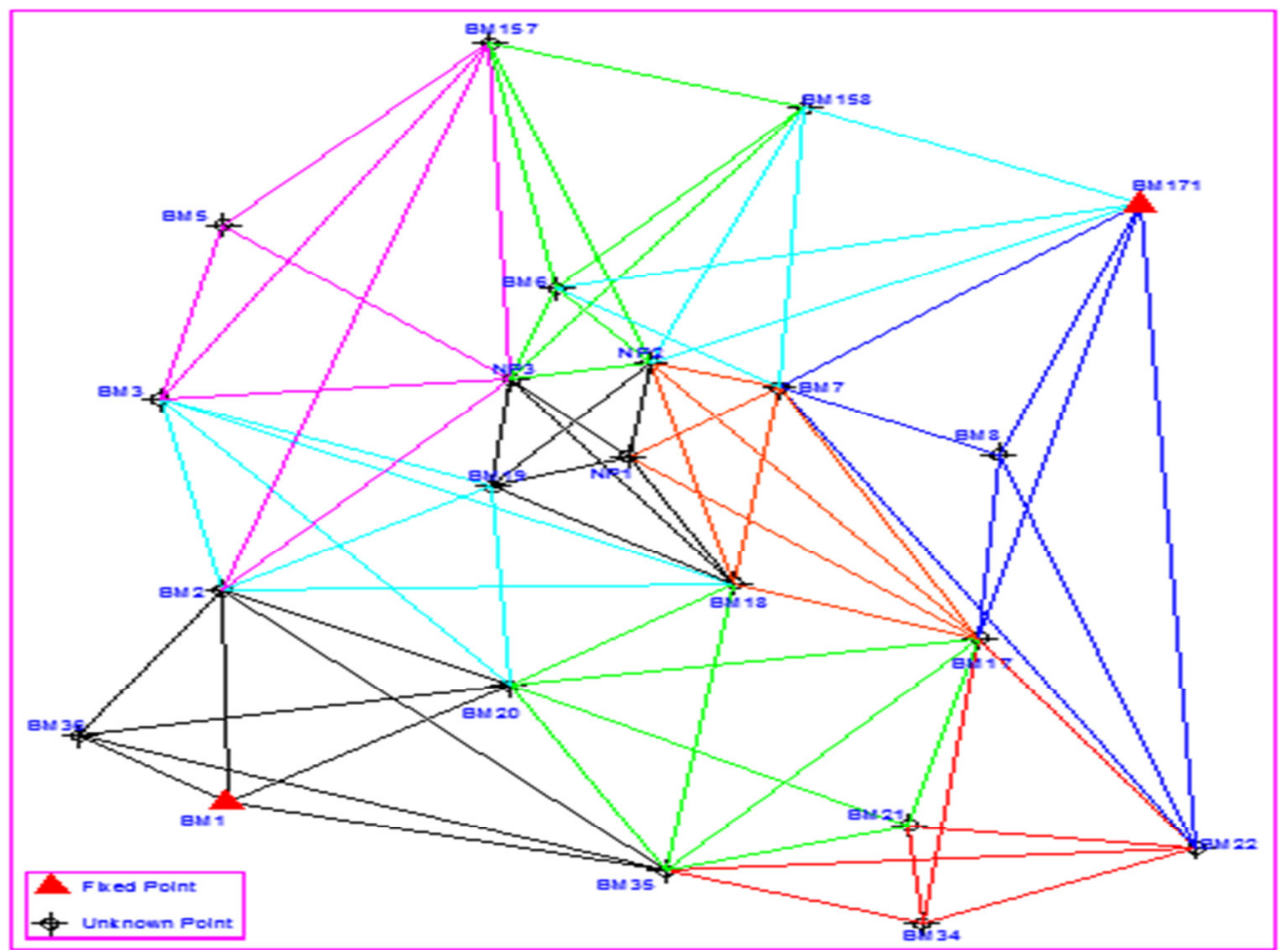

Figure 6. GPS over-constrained network with observation sessions 
Table (2): Reference points coordinates with HZ and VL precision of GPS measurements, orthometric heights and geoid undulations.

\begin{tabular}{|c|c|c|c|c|c|c|c|}
\hline \multirow{2}{*}{ Point ID } & \multirow{2}{*}{ Northing } & \multirow{2}{*}{ Easting } & \multirow{2}{*}{ h Ellipsoid } & \multicolumn{2}{|c|}{$\begin{array}{c}\text { GPS measurements } \\
\text { Precision }\end{array}$} & \multirow{2}{*}{ H Geoid } & \multirow{2}{*}{ Geoid Undulation $\mathbf{N}$} \\
\hline & & & & $\begin{array}{c}\text { HZ. } \\
\text { (meter) }\end{array}$ & $\begin{array}{c}\text { VL. } \\
\text { (meter) }\end{array}$ & & \\
\hline NP1 & 2377290.997 & 524804.891 & 35.164 & 0.017 & 0.035 & 30.400 & 4.764 \\
\hline NP2 & 2377552.250 & 526468.150 & 45.755 & 0.011 & 0.019 & 40.939 & 4.816 \\
\hline NP3 & 2375923.788 & 526169.910 & 41.773 & 0.009 & 0.016 & 36.995 & 4.778 \\
\hline BM1 & 2372598.804 & 518686.339 & 6.607 & Fixed & Fixed & 1.960 & 4.647 \\
\hline BM2 & 2372547.126 & 522417.938 & 18.756 & 0.019 & 0.017 & 14.108 & 4.648 \\
\hline BM3 & 2371814.606 & 525822.383 & 34.849 & 0.011 & 0.018 & 30.173 & 4.676 \\
\hline BM5 & 2372552.563 & 528913.032 & 54.861 & 0.009 & 0.016 & 50.050 & 4.811 \\
\hline BM6 & 2376453.755 & 527787.790 & 52.311 & 0.01 & 0.02 & 47.557 & 4.754 \\
\hline BM7 & 2379054.010 & 526035.305 & 44.061 & 0.009 & 0.019 & 39.235 & 4.826 \\
\hline BM8 & 2381621.695 & 524830.129 & 41.114 & 0.017 & 0.026 & 36.237 & 4.877 \\
\hline BM17 & 2381395.720 & 521579.438 & 19.532 & 0.011 & 0.02 & 14.795 & 4.737 \\
\hline BM18 & 2378523.168 & 522548.554 & 23.562 & 0.014 & 0.048 & 18.814 & 4.748 \\
\hline BM19 & 2375706.652 & 524274.147 & 30.460 & 0.015 & 0.024 & 25.705 & 4.755 \\
\hline BM20 & 2375892.499 & 520735.530 & 13.958 & 0.02 & 0.047 & 9.271 & 4.687 \\
\hline BM21 & 2380567.375 & 518256.019 & 10.915 & 0.019 & 0.031 & 6.179 & 4.736 \\
\hline BM22 & 2383928.094 & 517849.380 & 15.952 & 0.017 & 0.036 & 11.236 & 4.716 \\
\hline BM34 & 2380722.221 & 516520.999 & 6.356 & 0.011 & 0.025 & 1.555 & 4.801 \\
\hline BM36 & 2370880.532 & 519845.662 & 7.781 & 0.015 & 0.018 & 3.244 & 4.537 \\
\hline BM35 & 2377724.088 & 517451.287 & 6.398 & 0.011 & 0.017 & 1.646 & 4.752 \\
\hline BM157 & 2375672.962 & 532141.434 & 91.859 & 0.01 & 0.027 & 87.042 & 4.817 \\
\hline BM158 & 2379348.322 & 530995.611 & 76.367 & 0.017 & 0.019 & 71.535 & 4.832 \\
\hline BM171 & 2383279.085 & 529279.511 & 89.131 & Fixed & Fixed & 84.108 & 5.023 \\
\hline
\end{tabular}

\subsection{Creating Local Geoid Model for the Study Area}

The main objective of this research is to assess the quality of obtained orthometric heights from GPS measurements using a local geoid model as an alternative method of geometric leveling techniques. After obtaining ellipsoid heights from GPS measurements, and orthometric heights from leveling technique for reference points along the study area, we will compute geoid undulation values for these points using equation no.(1) as shown in table (2).

In order to calculate the value of geoid undulation in the whole study area based on the reference points, a local geoid model is created using the interpolation kriging interpolation method.

Two different local geoid models were created and investigated along the study area (Figure 7). The first model covers only a part of the study area which contains the newly established or densified reference points. The second model covers the whole study area and contains all available reference points except the newly established ones. The purpose of creating these two different models is to study and compare the effect of densification (increasing) of reference points along the study area on the precision of orthometric height extracted from these local geoid models. The characteristics of these two models are shown in table (3). Reference points along each model area are divided into two groups. The first group was used in the creation of the geoid model, while the second group of these points was used as check points to investigate the obtained precision of each geoid models. Note that one of these check points (NP3) is mutual to both models to be compared.

Table (3): The characteristics of the two generated geoid models

\begin{tabular}{|c|c|c|c|c|c|c|}
\hline \multirow[b]{2}{*}{ Created model } & \multicolumn{2}{|c|}{$\begin{array}{l}\text { Number of the used } \\
\text { reference points }\end{array}$} & \multirow{2}{*}{$\begin{array}{c}\text { Model } \\
\text { Covered } \\
\text { area } \\
\left(\mathbf{k m}^{2}\right)\end{array}$} & \multicolumn{3}{|c|}{ Distances between reference points statistics } \\
\hline & $\begin{array}{c}\text { for } \\
\text { creating } \\
\text { the model }\end{array}$ & $\begin{array}{l}\text { for testing } \\
\text { the model }\end{array}$ & & $\begin{array}{c}\text { Minimum } \\
\text { distance }(\mathbf{k m})\end{array}$ & $\begin{array}{c}\text { Maximum } \\
\text { distance } \\
(\mathbf{k m})\end{array}$ & $\begin{array}{c}\text { Average of } \\
\text { distances } \\
(\mathrm{km})\end{array}$ \\
\hline $\begin{array}{c}\text { First local geoid } \\
\text { model }\end{array}$ & 6 points & 2 points & 15.74 & 1.516 & 5.633 & 3.329 \\
\hline $\begin{array}{c}\text { Second local geoid } \\
\text { model }\end{array}$ & 17 points & 3 points & 140.14 & 2.073 & 6.986 & 4.271 \\
\hline
\end{tabular}




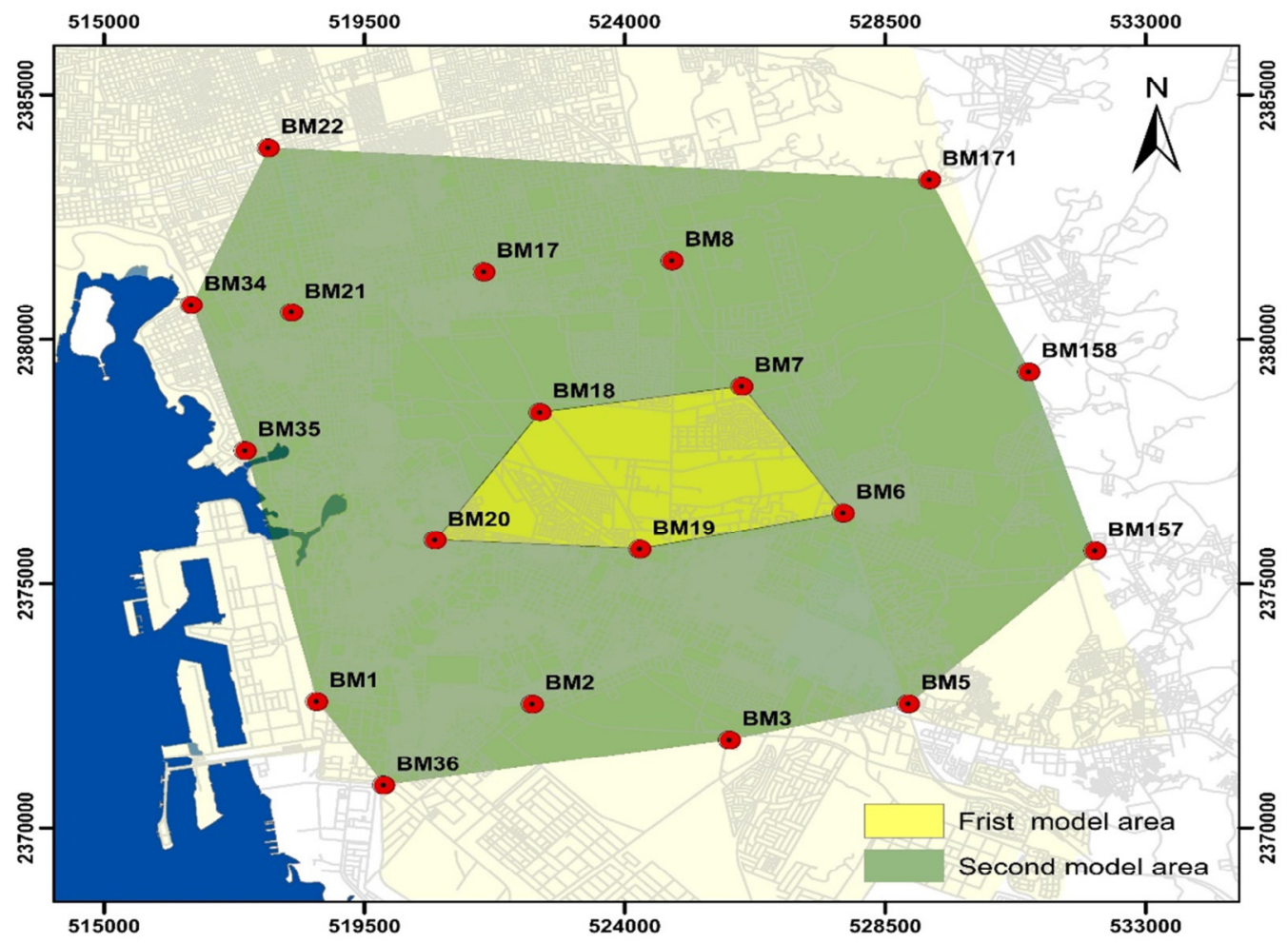

Figure 7. Areas of the two local geoid model for the study area.

\section{Results and Discussion}

The results obtained from the two local geoid models are presented and discussed in the following sections.

\subsection{First Local Geoid Model}

Figure (8) shows geoid undulation values of the first local geoid mode. Table (4) represents the assessment of orthometric heights of the two check points used for this model. The results indicate that difference between geoid undulations values estimated from the created local geoid model and obtained from GPS/leveling measurements ranges between $(1.1) \mathrm{cm}$ and $(-0.7) \mathrm{cm}$. In addition, the standard deviation map that results from the kriging interpolation of the first local geoid model shows a maximum of $42 \mathrm{~mm}$ (Figure 9).

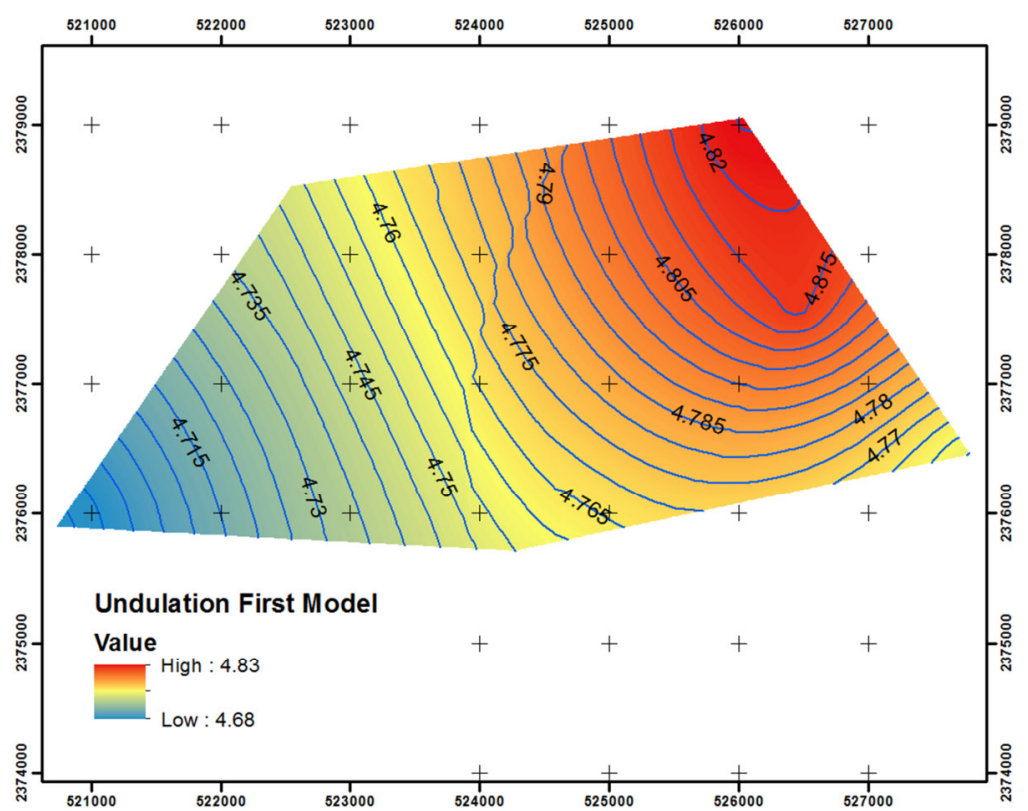

Figure 8. Undulations value of the first local geoid model in meter 


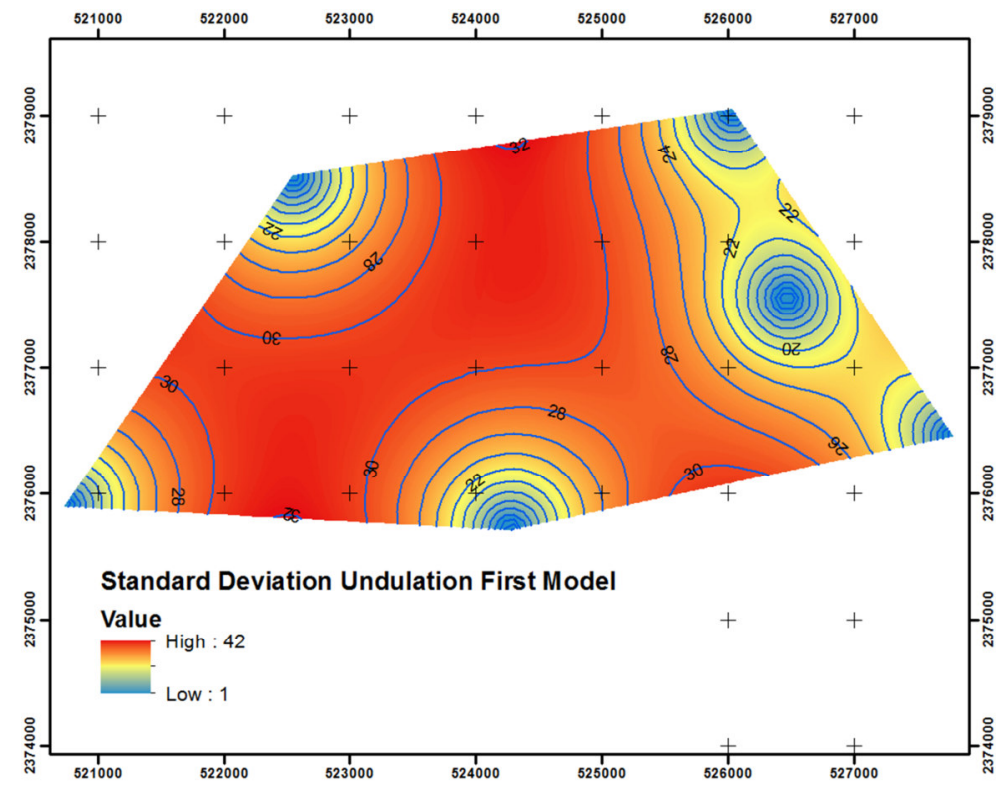

Figure 9. Standard deviation values of the undulation that corresponds to the first local geoid model in millimeter.

Table (4): First geoid model test points data.

\begin{tabular}{|c|c|c|c|c|c|c|}
\hline \multirow{2}{*}{$\begin{array}{c}\text { Test } \\
\text { point } \\
\text { ID }\end{array}$} & \multirow{2}{*}{$\begin{array}{c}\text { GPS } \\
\text { Ellipsoid } \\
\text { height (m) }\end{array}$} & \multirow{2}{*}{$\begin{array}{c}\text { Leveling } \\
\text { Geoid } \\
\text { height (m) }\end{array}$} & \multirow{2}{*}{$\begin{array}{c}\text { GPS/leveling } \\
\text { Geoid } \\
\text { undulation } \\
\text { (m) }\end{array}$} & \multicolumn{2}{|c|}{ local Geoid model } & \multirow{2}{*}{$\begin{array}{c}\text { Geoid } \\
\text { Undulation } \\
\text { difference } \\
\text { (m) }\end{array}$} \\
\hline & & & & $\begin{array}{c}\text { Geoid } \\
\text { undulation } \\
\text { (m) }\end{array}$ & $\begin{array}{c}\text { Orthometric } \\
\text { height (m) }\end{array}$ & \\
\hline NP3 & 41.773 & 36.995 & 4.778 & 4.771 & 37.002 & -0.007 \\
\hline NP1 & 35.164 & 30.400 & 4.7642 & 4.775 & 30.389 & 0.011 \\
\hline
\end{tabular}

\subsection{Second Geoid Model Results}

Geoid undulation values of the second geoid model created for the whole study area are shown in figure (10). The results of the three check points used for evaluating the quality of this model are shown in table (5). The results indicate that differences of estimated and obtained geoid undulations values are ranges between $(1.8) \mathrm{cm}$ and $(-1.1) \mathrm{cm}$. Also, the maximum standard deviation value for the second local geoid model is $56 \mathrm{~mm}$ (Figure $11)$. 


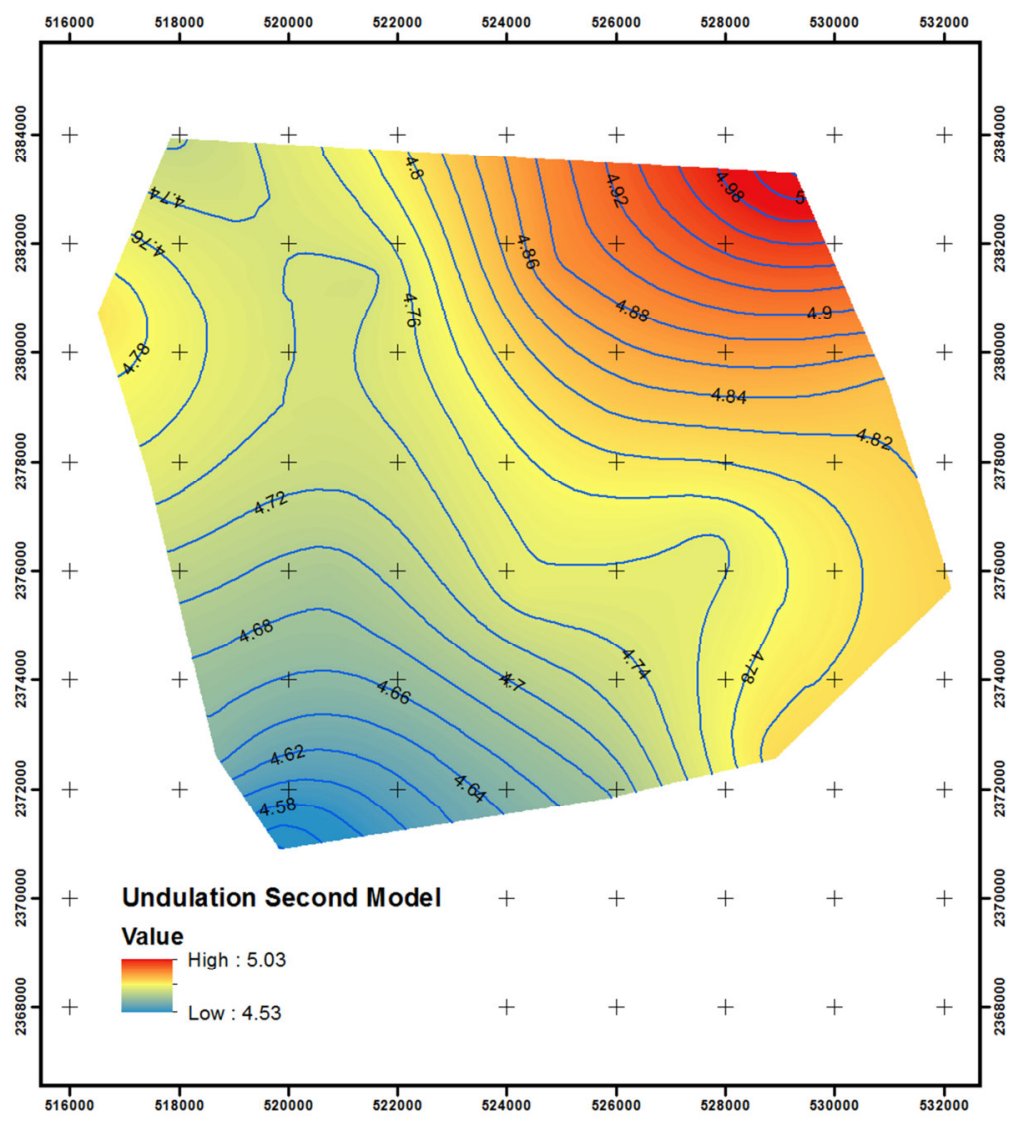

Figure 10. Undulations value of the second local geoid model in meter

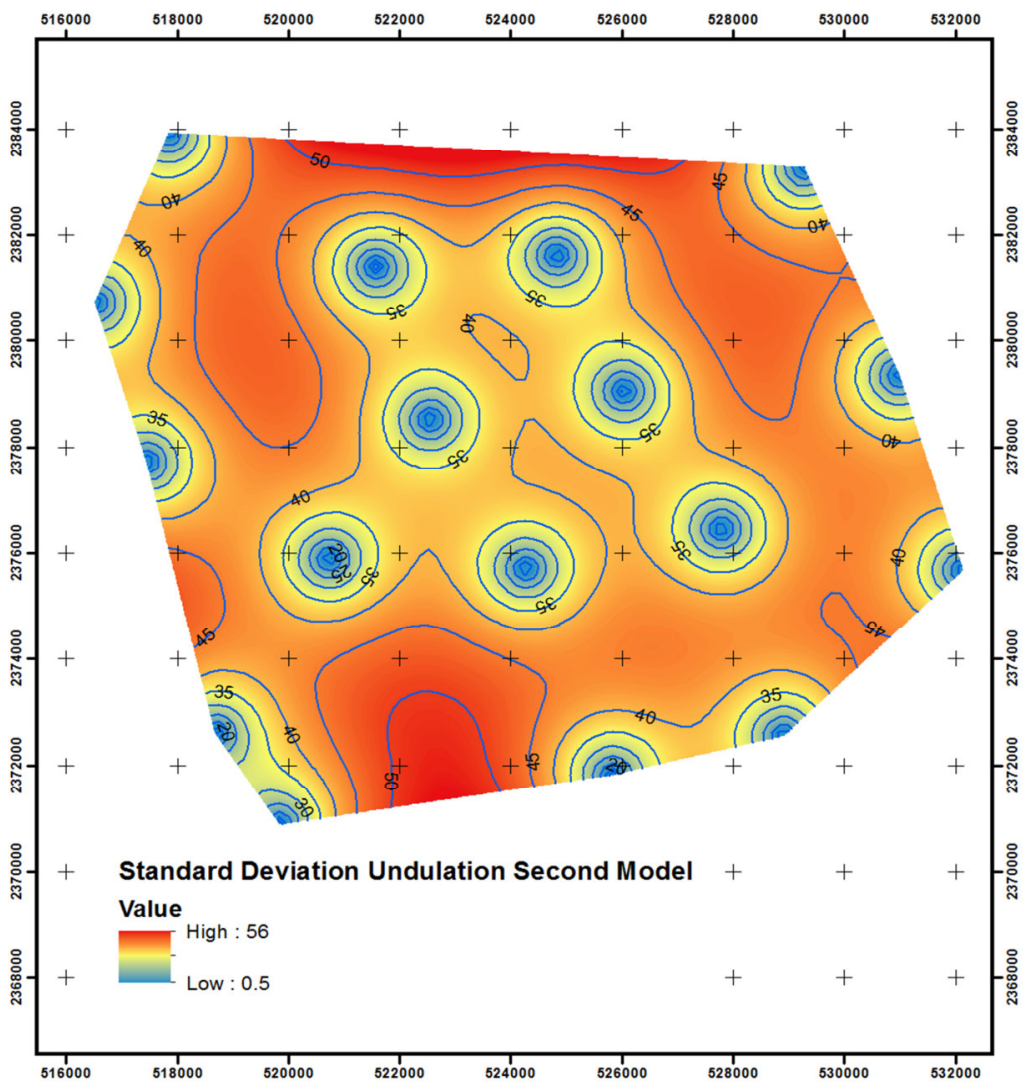

Figure 11. Standard deviation values of the undulation that corresponds to the second local geoid model in millimeter. 
Table (5): Second geoid model test points data.

\begin{tabular}{|c|c|c|c|c|c|c|}
\hline \multirow{2}{*}{$\begin{array}{c}\text { Test } \\
\text { point } \\
\text { ID }\end{array}$} & $\begin{array}{c}\text { GPS } \\
\text { Ellipsoid } \\
\text { height (m) }\end{array}$ & $\begin{array}{c}\text { Leveling } \\
\text { height (m) }\end{array}$ & $\begin{array}{c}\text { GPS/leveling } \\
\text { undulation (m) }\end{array}$ & $\begin{array}{c}\text { local Geoid model } \\
\text { undulation (m) }\end{array}$ & $\begin{array}{c}\text { Orthometric } \\
\text { height (m) }\end{array}$ & $\begin{array}{c}\text { Geoid } \\
\text { Undulation } \\
\text { difference } \\
\text { (m) }\end{array}$ \\
\hline NP3 & 41.773 & 36.995 & 4.778 & 4.7675 & 37.0055 & -0.0105 \\
\hline BM2 & 18.756 & 14.108 & 4.648 & 4.637 & 14.119 & -0.011 \\
\hline BM21 & 10.915 & 6.179 & 4.736 & 4.754 & 6.161 & 0.018 \\
\hline
\end{tabular}

\subsection{Discussion}

From comparing the results corresponding to the two generated models, we notice that the first model gives higher precision than the second model. This is mainly due to the more densified points and short separated distances between reference points of the first model. More specifically, the check point (NP3), which existed in both models, shows that the calculated geoid undulation difference is $0.69 \mathrm{~cm}$ and $1.05 \mathrm{~cm}$ from the first model and second model respectively. Also, the standard deviation maps show that first model (with a maximum standard deviation value of $42 \mathrm{~mm}$ ) is more precise than the second model (with a maximum standard deviation value of $56 \mathrm{~mm}$ ). However, it is very important to mention that the two models give an acceptable standard deviation for orthometric heights in surveying works that corresponds to $10 \mathrm{~cm}(2 \sigma$ for $95 \%$ confidence interval).

\section{Conclusion and Recommendations}

Orthometric height is a very important information that is crucial for several geodetic applications. However, the classical methods for obtaining this kind of height (such geometric leveling) are very time and money consuming. The conversion of the ellipsoid heights obtained from GPS measurements into orthometric heights becomes recently an important alternative thanks to the rapid growth of GNSS solutions. The aim of this paper is to study the efficiency and the potential of using local geoid model method for extracting orthometric heights from ellipsoid heights.

GPS/Leveling methods are the simplest and popular methods used in the creation of local geoid models. Precise leveling and differential GPS should be used to determine orthometric and ellipsoid height of reference points with a high precision to increase the accuracy of the obtained heights from the appropriate interpolation method. The Kriging method is one of the best interpolation methods that allows predicting the value of undulation while characterizing the corresponding the precision of predications.

Based on the analysis of the obtained results, creating a local geoid model is an effective method for obtaining orthometric height using GPS observations instead of levelling works. This can reduce the field-time of the survey and, as a consequence, saving costs of this field works. However, to achieve the required precision, the study area has to be covered with sufficient and well distributed reference points. The number and location of these reference points depend mainly on the topography of the study area and the required precision of the local geoid model to be generated.

Finally, establishing a strong cooperation among local surveying organizations is highly recommended in order to create local geoid models. This kind of collaboration will facilitate sharing all available data and avoiding repetitive surveying works.

\section{REFRENCES}

Adm R. and Bossler John D. (1984): "Standards and Specifications of Geodetic Control Networks". Federal Geodetic Control Committee. http://www.ngs.noaa.gov/FGCS/tech_pub/1984-stds-specs-geodetic-controlnetworks.htm

Al-Krargy E. M., Doma M. I., and Dawod G. M. (2014): "Towards an accurate definition of the local geoid model in Egypt using GPS/Leveling, data: A case study at Rosetta Zone". International Journal of Innovative Science and Modern Engineering (IJISME), ISSN: 2319-6386,vol. 2, issue-11, October (2014).

Algarni, D.A. (1997): "Geoid modeling in Saudi Arabia". ITC Journal, 2: 114-120.

Alothman, A., Gruber, T., and Bouman, J. (2011): "Analysis of gravimetric and GPS/levelling derived geoids for Saudi Arabia". In 2011 General Assembly of the European Geosciences Union, 3-8 April 2011.

Alothman, A., Gruber, T., and Bouman, J. (2012): "Evaluation of height system biases for regional levelling network in Saudi Arabia using EGM08 and GOCE models". In 2012 General Assembly of the European Geosciences Union, 22-27 April 2012.

Alothman, A., Gruber, T., and Bouman, J. (2013): "Evaluation of height system biases for regional levelling network in Saudi Arabia using EGM08 and GOCE models". In 2013 General Assembly of the European Geosciences Union, 7-12 April 2013.

Alrajhi, M., Yanar, R., Hawarey, M., and Alomar, A. (2009): "Evaluation of height system biases for regional levelling network in Saudi Arabia using EGM08 and GOCE models". In 2009 General Assembly of the 
European Geosciences Union, 19-24 April 2009.

Chen Y., and Yang Z. (2001):“A Hybrid method to determine the Hong Kong Geoid”. International Conference, FIG Working Week 2001, Seoul, Korea, 6-11 May 2001.

El-Hallaq M. (2012): "Development of a local GPS/leveling geoid model for the Gaza strip area", International Journal of Emerging Technology and Advanced Engineering, ISSN 2250-2459, Volume 2, Issue 3, March 2012, pp. 268-273.

El-Shouny A. and Yakoub N. (2015) : "Comparative study of different surface fitting methods for geoid modeling along the Rosetta coastal zone area" . Regional Conference on Surveying \& Development, Sharm El-Sheikh, Egypt, 3-6 October 2015.

El Shouny A., Yakoub N. and Hosny M. (2017): "Evaluating the performance of Using PPK-GPS Technique in Producing Topographic Contour Map". Marine Geodey, Published online: 27 Apr 2017. http://dx.doi.org/10.1080/01490419.2017.1321594

Erol B., and Çelik R.(2004): "Precise local geoid determination to make GPS technique more effective in practical applications of geodesy". FIG Working Week, Athens, Greece, May 22-27.

Erol, B., and Erol, S. (2013): "Learning-based computing techniques in geoid modeling for precise height transformation." Computer Geosciences, 107 - 95, 52.

Featherstone, W. (2000): "Refinement of gravimetric geoid using GPS and leveling data." Journal of Surveying Engineering ,10.1061/(ASCE)0733-9453(2000)126: 2(27), 27-56.

Featherstone, W. E., Dentith, M. C., and Kirby, J. F. (1998): "Strategies for the accurate determination of orthometric heights from GPS.” Survey Review, 34(267), 278-296.

Förste, C., Flechtner, F., Schmidt, R., König, R., Meyer, U., Stubenvoll, R., ... \& Bruinsma, S. (2006). "Global mean gravity field models from combination of satellite mission and altimetry/gravimetry surface data." In Geophysical Research Abstracts (Vol. 8, p. 03462), November, 2006.

Fotopoulos, G. (2005): "Calibration of geoid error models via a combined adjustment of ellipsoidal, orthometric and gravimetric geoid height data." Journal of Geodesy, 79(1-3), 111-123.

Fotopoulos, G., Kotsakis, C., and Sideris, M. G. (2003): "How accurately can we determine orthometric height differences from GPS and geoid data?" Journal of Surveying Engineering, 10.1061/(ASCE)07339453(2003)129:1(1), 1-10.

Hofmann-Wellenhof, B., \& Moritz, H. (2006). "Physical geodesy". Springer Science \& Business Media.

Longley P. A., Goodchild M., Maguire D. J., Rhind D. W. (2010): "Geographic Information Systems and Science (3rd Edition)", John Wiley \& Sons.

Ngiboglu, S.M. (2008): "Final report on the determination of the geoid for the Kingdom of Saudi Arabia". Internal document NASA/TP-1998-206861. General Directorate of Military Survey, GDMS. Riyadh, Saudi Arabia.

Oliver M. A., Webster R., Kriging (1990): "a method of interpolation for geographical information systems". International Journal of Geographical Information Systems, 4, 3, pp. 313-332.

Pavlis, N.K., Holmes, S.A., Kenyon, S.C., and Factor, J.K. (2012): "The development and evaluation of the Earth Gravitational Model 2008 (EGM2008)". Journal of Geophysical Research, 117(B4). doi:10.1029/2011JB008916.

Qulin Tan and Xiao Xu (2014): " Comparative Analysis of Spatial Interpolation Methods: an Experimental Study". Sensors \& Transducers, Vol. 165, Issue 2, February 2014, pp. 155-163.

Seyed Mohsen Khazraei; Vahab Nafisi; Ali Reza Amiri-Simkooei, M.ASCE; and Jamal Asgari (2016): "Combination of GPS and Leveling Observations and Geoid Models Using Least-Squares Variance Component Estimation". Journal of Surveying Engineering, (C) ASCE, ISSN 0733-9453.

Soltanpour, A., Nahavandchi, H., and Featherstone,W. E. (2006): "The use of second-generation wavelets to combine a gravimetric quasigeoid model with GPS-levelling data.” Journal of Geodesy, 80(2), 82-93.

Tripathi R.K. andTripathi M. (2015): "Development of Geoid Model for Chhattisgarh State using Geophysical Methods and GPS Technology" . 4th Int'l Conference on Advances in Engineering Sciences \& Applied Mathematics (ICAESAM'2015) Dec. 8-9, 2015 Kuala Lumpur (Malaysia).

You, R. J. (2006): "Local geoid improvement using GPS and leveling data: Case study." Journal of Surveying Engineering ,10.1061/(ASCE)0733-9453(2006)132: 3(101), 101-107.

Zhong, D. (1997): "Robust estimation and optimal selection of polynomial parameters for the interpolation of GPS geoid heights.” Journal of Geodesy, 71(9), 552-561. (C) 